\title{
Effect of Arginine and Vitamin E Supplementation on Delayed Foot Web Reaction to Killed Staphylococcus aureus in Experimental T-2 Mycotoxicosis in Broiler Chicken
}

\author{
B.K. Ramesh ${ }^{1}$, H.D. Narayanaswamy ${ }^{2}$, M.L. Satyanarayana ${ }^{3}$, \\ Suguna $\mathrm{Rao}^{3}$ and Srikrishna Isloor ${ }^{4}$
}

\author{
${ }^{1}$ ICAR-Krishi Vigyan Kendra, Hagari- 583 111, Ballari (Tq), Karnataka, India \\ ${ }^{2}$ Karnataka Veterinary Animal Fisheries Sciences University, Bidar, Karnataka, India \\ ${ }^{3}$ Department of Veterinary Pathology, ${ }^{4}$ Department of Veterinary Microbiology, Veterinary \\ College, Hebbal, Bengaluru -560 024, India
}

*Corresponding author

\section{Keywords \\ Broiler chicken, T-2 \\ Toxin, Arginine, \\ Vitamin E, DTH \\ response, \\ Immunomodulation \\ Article Info \\ Accepted: \\ 12 March 2019 \\ Available Online: \\ 10 April 2019}

\section{A B S T R A C T}

The toxic effect of different dietary levels of T-2 toxin on cell-mediated arm of immune system was assessed by eliciting delayed foot web reaction (DFWR) in broiler chicken. The nutritional immunomodulation using arginine (ARG) $[22 \mathrm{~g} / \mathrm{kg}$ ] and vitamin E (VE) [80 mg/kg] supplementation was attempted. A total of 144 day old commercial broiler chicks were randomly divided into six groups. The first four groups received 0.0 (ControlGroup I), $0.25 \mathrm{ppm}$ (Group II), 0.50ppm (Group III) and 1ppm (Group IV) of dietary T-2 toxin. The ARG and VE combination was supplemented in the diet of birds fed either ' 0 ' (Group V) or 1ppm (Group VI) of T-2 toxin. The test diets were fed for 0-28 days. The birds were sensitized twice on days 14 and 21 with killed $S$. aureus antigen and challenged intradermally in toe web on day 28. DFWR was measured at $0,6,24$, and $48 \mathrm{~h}$ post challenge. The foot web thickness peaked at $24 \mathrm{~h}$ post challenge. A significant $(\mathrm{P} \leq 0.05)$ reduction in DFWR was observed in birds fed with $1 \mathrm{ppm}$ of T-2 toxin compared to birds in control as well as ARG and VE supplemented groups. At 0.25 and $0.5 \mathrm{ppm}$ of T-2 toxin, the DFWR was similar to control. The DTH reaction to $S$. aureus antigen in birds fed 1 ppm of T-2 toxin and supplemented with ARG and VE was similar to control birds. ARG and VE complemented each other to offer immunoprotection to birds that received immunotoxicant T-2 toxin in their diet.

\section{Introduction}

T-2 toxin, a trichothecene mycotoxin produced by several species of genus Fusarium is a potent immunotoxicant and its immunosuppressive effects are the result of direct or indirect inhibition of protein synthesis (Corrier, 1991). Environmental conditions under which the broiler chickens are intensively raised are often less than optimal and feed supplied is invariably contaminated with mycotoxins. The unending 
stress on broiler chicken to attain desirable market weight will be further amplified, if the feed is contaminated even with low levels of immunosuppressive agents like $\mathrm{T}-2$ toxin leading to lowered immunity and increased risk of diseases (Vander Zijpp 1983; Monreal and Paul, 1989).

The delayed type hypersensitivity (DTH) response is one of a predictive immune tests that has been used as an indicator of cellmediated immune status which is $\mathrm{T}$ helper 1 (Th1) dependent response along with cell recruitment and chemotaxis to the local site (Dietert et al., 2010). Delayed-type hypersensitivity reaction to $S$. aureus has been established for wattle (Cotter et al., 1987) and foot pad (Zhu et al., 1999) in poultry. In the present study, toxic effect of T-2 toxin on cell-mediated arm of immune system was assessed by eliciting delayed foot web reaction (DFWR), a DTH reaction in the foot pad of birds.

The critical needs of certain nutrients which play an important role in immunological processes form the basis of nutritional immunomodulation (Humphrey, 2005). Arginine (ARG) and vitamin E (VE) are two such nutrients whose mechanisms of immunomodulation have been identified. ARG regulates T-cell development and generates nitric oxide as an effector molecule in activated tissues macrophages.

Vitamin E as an antioxidant, protects cells against immunopathology and also has been known to enhance lymphocyte proliferation. However, the immunomodulatory properties of these nutrients are achieved when their levels in the diet are included above their requirement for growth (Leshchinsky and Klasing, 2001, 2003). Hence, ARG and VE above NRC (1994) recommendation have been supplemented in the present study to assess their immunomodulatory effect in broiler chickens fed different dietary levels of $\mathrm{T}-2$ toxin.

\section{Materials and Methods}

\section{Production of T-2 toxin}

The T-2 toxin was produced on whole wheat using Fusarium sporotrichoides MTCC 1894 (Burmeister, 1971) and quantified using thin layer chromatography at Animal Feed Analytical and Quality Assurance Laboratory (AFAQAL), Veterinary College and Research Institute, Namakkal, Tamilnadu, India.

\section{Toxicity trial}

One hundred and forty four unsexed day old commercial broiler chicks (Cobb) were procured from a reputed hatchery. The chicks were wing banded, weighed and housed in battery brooder with ad libitum supply of feed and water. They were randomly divided into six groups of 24 chicks each. The first four groups received 0.0 (Control-Group I), $0.25 \mathrm{ppm}$ (Group II), 0.50ppm (Group III) and 1ppm (Group IV) of dietary T-2 toxin. The ARG and VE combination was supplemented in the diet of birds fed either ' 0 ' (Group V) or 1ppm (Group VI) of T-2 toxin. The test diets were fed for 0-28 days.

The experimental trials were approved by the Institutional Animal Ethics Committee and were conducted under its guidelines. The broiler mash containing no toxin binders and free from mycotoxins was used in the experimental study. Weighed amounts of powdered wheat culture material containing known amounts of T-2 toxin was incorporated to yield three dietary T-2 levels of $0.25 \mathrm{ppm}$, $0.5 \mathrm{ppm}$ and $1 \mathrm{ppm}$. L- Arginine (Sigma Aldrich) and VE (Tocopheryl acetate adsorbed on precipitated silicon dioxide from Mercks Pvt. Ltd., Goa) were mixed in the feed to have final supplementation rate of 
$22 \mathrm{~g} / \mathrm{kg}(2.2 \%)$ and $80 \mathrm{mg} / \mathrm{kg}$ respectively. The test diets were fed for 28 days from the day of hatch.

\section{Delayed foot web reaction (DFWR)}

Delayed-type hypersensitivity (DTH) reaction to Staphylococcus aureus (obtained from the Department of Veterinary Microbiology, Veterinary College, Bangalore) was studied in the footpad of birds. The method described by Cotter et al., (1987) in eliciting DTH reaction in broiler chicken using killed $S$. aureus antigens was followed for eliciting delayed foot web reaction (DFWR).

Six birds were randomly identified in each group. They were sensitized on days 14 and 21 of toxicity trial. For each sensitizing dose, chicks were injected subcutaneously in the neck region with $0.2 \mathrm{ml}$ of killed $S$. aureus (3 $\mathrm{X} 10^{8}$ organisms per bird) diluted 1:1 with polyethylene glycol.

On day 28, each chick was challenged intradermally in the toe web between 3rd and 4th digits of the right foot with $0.1 \mathrm{ml}$ of 1.5 $\mathrm{X} 10^{8}$ of $S$. aureus diluted 1:1 with sterile PBS. Corresponding toe web of the left foot was injected with $100 \mu$ of sterile PBS alone.

The thickness of toe web was measured at 0 , 6,24 , and 48 h post challenge using Vernier scale. Changes in thickness of the toe web were referred to as DFWR and calculated using the following formula.

DFWR $=\quad$ Thickness of the toe web of the right foot ( $S$. aureus) - thickness of the toe web of the left foot (PBS).

\section{Histopathology}

After $48 \mathrm{~h}$, the tissue samples of the injected areas were collected in 10 per cent neutral buffered formalin (NBF) for histopathological examination. They were processed through routine paraffin embedding technique. Paraffin embedded tissues were sectioned to 4 $\mu \mathrm{m}$ thickness and stained by Haematoxylin and Eosin (H\&E) as per Luna (1968) for histopathological examination.

The experimental data were subjected to one way analysis of variance as per Snedecor and Cochran (1989) using SPSS17 statistical package.

\section{Results and Discussion}

\section{Delayed Foot Web Reaction (DFWR)}

Mean $( \pm$ SE) foot web thickness in broiler birds of different treatment groups after inducing DTH reaction using killed $S$. aureus antigen at $0,6,24$ and $48 \mathrm{~h}$ post challenge is depicted in Table 1.

An increase in mean foot web thickness was noticed in birds of all the groups at $6 \mathrm{~h}$ post challenge and reached peak by $24 \mathrm{~h}$. The foot web thickness recorded in birds fed with 1 ppm of $\mathrm{T}-2$ toxin was significantly $(\mathrm{P} \leq 0.05)$ lower compared to the thickness observed in birds supplemented with ARG and VE at $6 \mathrm{~h}$ post challenge. But the values were not significant when compared to the thickness recorded in control birds.

However, when the thickness peaked at $24 \mathrm{~h}$ post challenge in all the groups, birds which received $1 \mathrm{ppm}$ of dietary $\mathrm{T}-2$ toxin recorded a significantly $(\mathrm{P} \leq 0.05)$ lower foot web thickness compared to the thickness recorded in control birds and the ones that received ARG and VE supplementation in their toxin free diet (Figure 1). The trend remained same even at $48 \mathrm{~h}$ post challenge. A similar reduction in DTH response was earlier recorded by Ramaswamy et al., (2010) in T-2 toxin $(1 \mathrm{ppm})$ treated broiler chicken. The T-2 toxin induced necrosis and depletion of 
lymphocytes in the thymus, bursa of Fabricius and spleen (Wyatt et al., 1973; Kamalavenkatesh et al., 2005; Yohannes et al., 2012, Ramesh et al., 2014) could be cited as reason for poor DTH response elicited in toxin fed birds. The delayed foot web reaction however, was not reduced significantly at 0.25 and $0.5 \mathrm{ppm}$ of dietary T-2 toxin.

ARG and VE supplemented birds maintained on toxin free diet recorded numerical increase in foot web thickness which was not significant with the thickness recorded in control birds but the values were significantly $(\mathrm{P} \leq 0.05)$ higher compared to the values in birds fed 1ppm of T-2 toxin at 6,24 and $48 \mathrm{~h}$ post challenge.

There are conflicting results on effect of different levels of VE in eliciting cutaneous basophil hypersensitivity (CBH) response, a CMI response to phytohemagglutinin A (PHA). Leshchinsky and Klasing (2001) observed dietary supplements of VE $(0,10$, $17.5,25,37.5,50,100$ and $200 \mathrm{IU} / \mathrm{kg}$ ) did not influence in $\mathrm{CBH}$ response. Boa-Amponsem et al., (2002), however, observed a reduction in $\mathrm{CBH}$ response at higher dietary VE level (300 $\mathrm{mg} / \mathrm{kg}$ ) compared to NRC recommended VE level of $10 \mathrm{mg} / \mathrm{kg}$. While, a considerable protection against in vitro $\mathrm{T}-2$ toxin inhibition of lymphocyte proliferation in response to mitogens was shown by water soluble form of VE (Jaradat et al., 2006).

Higher dietary levels of arginine stimulated lymphocyte proliferation, IL-2 and $\gamma$-IFN production (Emadi et al., 2010; 2011; Lee et al., 2002; Tayade et al., 2006) which were indicative of enhanced cellular immunity. The $\mathrm{CBH}$ response to PHA was enhanced in birds supplemented with 2\% arginine (Munir et al., 2009). The present study also indicated enhanced DTH response in arginine supplemented birds. Thus it can be construed that ARG supplementation helped in improving cellular immune response. The birds fed with $1 \mathrm{ppm}$ of T-2 toxin and further supplemented with ARG and VE showed foot web thickness which did not differ significantly with the values recorded in control birds during all the post challenge intervals. The antioxidant property of VE against free radical damage might have helped in maintaining cellular integrity in lymphoid organs, which is key to receive and respond to the messages needed to coordinate the immune response (Klasing, 1997; Watkins, 1991).

Table.1 Mean ( \pm SE) foot web thickness $(\mathrm{mm})$ during post challenge interval (h)

\begin{tabular}{|c|c|c|c|c|c|c|c|}
\hline & $\begin{array}{c}\text { T-2 } \\
\text { toxin } \\
(\boldsymbol{\mu g} / \mathbf{g})\end{array}$ & $\begin{array}{c}\text { ARG } \\
(\mathbf{2 2 g} / \mathbf{k g})\end{array}$ & $\begin{array}{c}\text { VE } \\
(\mathbf{8 0} \mathbf{~ m g} / \mathbf{k g})\end{array}$ & \multicolumn{4}{|c|}{ Post challenge intervals } \\
\cline { 3 - 8 } & & & $\mathbf{0 ~ h}$ & $\mathbf{6 h}$ & $\mathbf{2 4 h}$ & $\mathbf{4 8 h}$ \\
\hline $\mathbf{I}$ & - & - & - & $0.15^{\mathrm{a}} \pm 0.04$ & $0.65^{\mathrm{ab}} \pm 0.08$ & $0.68^{\mathrm{b}} \pm 0.06$ & $0.58^{\mathrm{b}} \pm 0.06$ \\
\hline II & 0.25 & - & - & $0.18^{\mathrm{a}} \pm 0.04$ & $0.63^{\mathrm{ab}} \pm 0.12$ & $0.63^{\mathrm{b}} \pm 0.08$ & $0.52^{\mathrm{ab}} \pm 0.07$ \\
\hline III & 0.50 & - & - & $0.18^{\mathrm{a}} \pm 0.03$ & $0.43^{\mathrm{ab}} \pm 0.06$ & $0.55^{\mathrm{ab}} \pm 0.06$ & $0.52^{\mathrm{ab}} \pm 0.06$ \\
\hline IV & 1.00 & - & - & $0.20^{\mathrm{a}} \pm 0.04$ & $0.38^{\mathrm{a}} \pm 0.04$ & $0.41^{\mathrm{a}} \pm 0.03$ & $0.40^{\mathrm{a}} \pm 0.06$ \\
\hline $\mathbf{V}$ & - & + & + & $0.18^{\mathrm{a}} \pm 0.04$ & $0.66^{\mathrm{b}} \pm 0.09$ & $0.72^{\mathrm{b}} \pm 0.07$ & $0.63^{\mathrm{b}} \pm 0.04$ \\
\hline VI & 1.00 & + & + & $0.18^{\mathrm{a}} \pm 0.03$ & $0.43^{\mathrm{ab}} \pm 0.06$ & $0.55^{\mathrm{ab}} \pm 0.05$ & $0.53^{\mathrm{ab}} \pm 0.04$ \\
\hline
\end{tabular}


Fig.1 Mean $( \pm$ SE) foot web thickness $(\mathrm{mm})$ during two different post challenge interval $(\mathrm{h})$

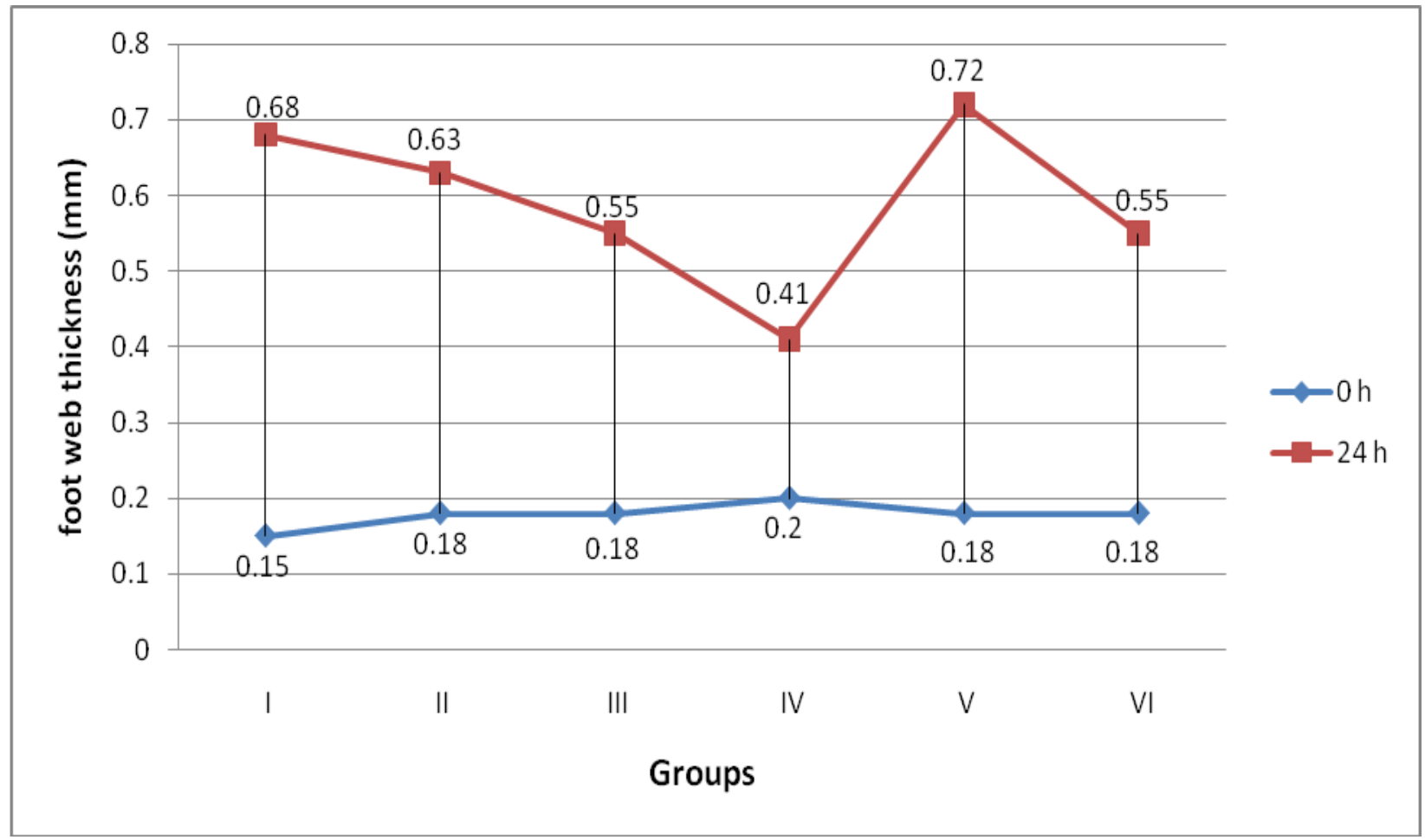

Fig.2 Section of foot web from Group V showing pronounced perivascular infiltration of mononuclear cells following sensitisation and challenge by killed S. aureus (H\&E x100)

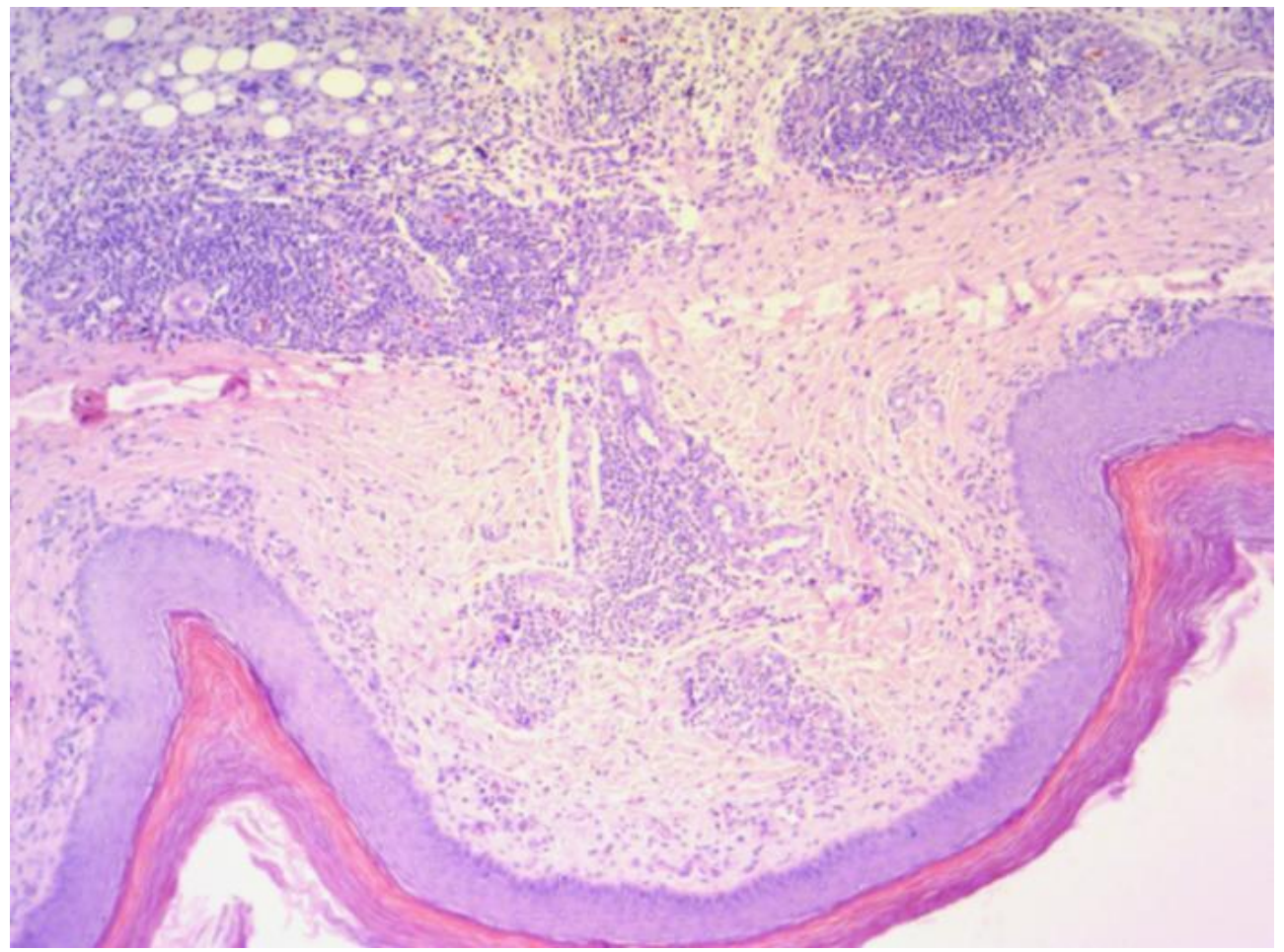


Fig.3 Section of foot web from Group VI bird showing diffuse edema and infiltration of heterophils, macrophages and lymphocytes following sensitisation and challenge by killed $S$. aureus (H\&E x400)

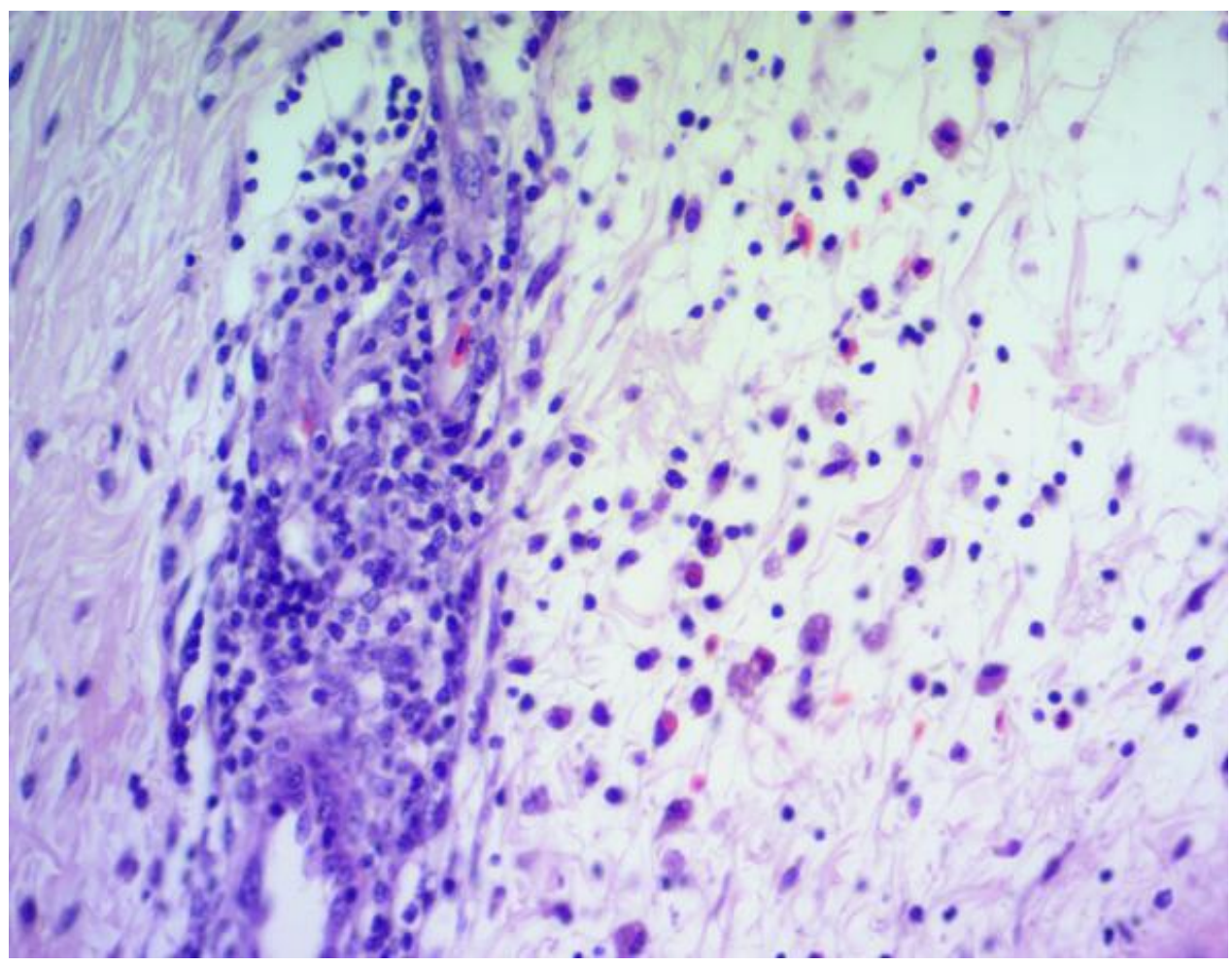

High levels of VE, 10 times greater than the required level have been found to be immunostimulatory (Latshaw, 1991). The level of VE $(80 \mathrm{mg} / \mathrm{kg})$ used in the present study in combination with $2.2 \%$ ARG which helps in $\mathrm{T}$ - cell development and function could have protected the birds against immunotoxic effect of T-2 toxin helping birds of this group to have the DTH response comparable to control birds.

Thus, ARG and VE complement each other in their immunoprotective action against a potent immunosuppressant, the T-2 toxin.

\section{Histopathology of inter digital web}

The microscopic lesions in the foot web of birds that were sensitised and later challenged by killed $S$. aureus were of similar kind in all the groups. The lesions included diffuse edema, perivascular infiltration of mononuclear cells, heterophils, macrophages and few plasma cells (Figure 2 and 3). The lesions recorded were in agreement with those observed earlier by Zhu et al., (1999) when they induced DTH reaction in chickens using killed $S$. aureus.

The lesions were pronounced in birds that received ARG-VE supplementation in their toxin free diet (Figure 2). Immunostimulatory effect of ARG-VE combination as discussed earlier in this section could be the reason for marked lesions recorded in this group. However, lesions were less conspicuous in birds that received $1 \mathrm{ppm}$ of $\mathrm{T}-2$ toxin in the control diet in comparison to the lesions observed in control birds. The lesions in birds fed $0.25 \mathrm{ppm}$ and $0.5 \mathrm{ppm}$ of $\mathrm{T}-2$ toxin were no different from that of control ones. Thus, dietary T-2 toxin at levels equal or more than 
$1 \mathrm{ppm}$ could result in poor DTH reaction. Further, birds fed with 1ppm of T-2 toxin and received ARG-VE supplementation, showed histological lesions similar to control ones and that supported our earlier inference on immunoprotective nature of $\mathrm{ARG}$ and $\mathrm{VE}$ combination in T-2 toxin fed birds.

\section{References}

Boa-amponsem, K., Price, S. E., Picard, M., Geraert, P. A. and Siegel, P. B., 2002. Vitamin $\mathrm{E}$ and immune responses of broiler pureline chickens. Poult. Sci., 79:466-470.

Burmeister, H.R., 1971. T-2 toxin production by Fusarium trinctium on solid substrate. Appl. Microbiol., 21: 739-742

Corrier, D. E., 1991. Mycotoxicosis: mechanisms of immunosuppression. Vet. Immunol. Immunopathol., 30:7387.

Cotter, P.F., Taylor, R.L. Jr., Wing, T.L. and Briles, W.E., 1987. Major histocompatability (B) complex associated differences in the delayed wattle reaction to staphylococcal antigen. Poult. Sci., 66: 203-208

Dietert, R.R., Bunn, T.L. and Lee, J.E., 2010. The delayed type hypersensitivity assay using protein and xenogeneic cell antigens. Methods Mol. Biol., 598: 185194.

Emadi, M., Jahanshiri, F., Azizi Jalalian, F., Kaveh, K., Bejo, M.H., Ideris, A., Assumaidaee, A.A. and Alimon, R. A., 2010. Immunostimulatory effects of arginine in broiler chickens challenged with vaccine strain of infectious bursal disease virus. Journal of Animal and Veterinary Advances, 9(3): 594-600.

Emadi, M., Jahanshiri, F., Kaveh, K., Hairbejo, M., Ideris, A. and Alimon, A. R., 2011. Nutrition and immunity: the effects of the combination of arginine and tryptophan on growth performance, serum parameters and immune response in broiler chickens challenged with infectious bursal disease vaccine. Avian Pathol., 40(1): 63-72.

Humphrey, B. D., 2005. Nutrient needs of the immune system. In: Proceedings of the 3rd Mid-Atlantic Nutrition Conference. Zimmermann, N.G., ed., University of Maryland, College Park, MD 20742 pp 58-69.

Jaradat, Z.W., Borja Vila and Marquardt, R.R., 2006. Adverse effects of T-2 toxin on chicken lymphocytes blastogenesis and its protection with vitamin $\mathrm{E}$. Toxicology, 225: 90-96.

Kamalavenkatesh, P., Vairamuthu, S., Balachandran, C., Murali Manohar, B. and Dhinakar Raj, G., 2005. Immunopathological effect of the my cotoxins cyclopiazonic acid and T-2 toxin on broiler chicken. Mycopathologia, 159: 273-279.

Klasing, K. C., 1997. Interaction between nutrition and infectious disease. In: Diseases of Poultry, B. W. Calnek, ed. Iowa State University Press, Ames, IA. pp 73-80.

Latshaw, J.D., 1991. Nutrition: mechanisms of immunosuppression. Vet. Immunol Immunopathol., 30(1): 111-120

Lee, J. E., Austic, R. E., Naqi, S. A., Golemboski, K. A. and Dietert, R. R., 2002. Dietary arginine intake alters avian leukocyte population distribution during infectious bronchitis challenge. Poult. Sci., 81:793-798.

Leshchinsky, T.V. and Klasing, K. C., 2001. Relationship between the level of dietary vitamin $\mathrm{E}$ and the immune response of broiler chickens. Poult. Sci., 80:1590-1599.

Leshchinsky, T.V. and Klasing, K.C., 2003. Profile of chicken cytokines induced by lipopolysaccharide is modulated by dietary alpha-tocopheryl acetate. Poult. Sci., 82:1266-1273. 
Luna, L.G., 1968. Manual of Histologic Staining Methods of the Armed Forces Institute of Pathology. McGraw Hill Book Company, New York.

Monreal, G., and G. Paul., 1989. Infectious disease factors in poultry. Berl. Munch. Tierarztl. Wochenschr., 102:405-409.

Munir, K., Muneer, M. A., Masaoud, E., Tiwari, A., Mahmud, A., Chaudhry, R. M. and Rashid, A., 2009. Dietary arginine stimulates humoral and cellmediated immunity in chickens vaccinated and challenged against hydropericardium syndrome virus. Poult. Sci., 88:1629-1638.

NRC., 1994. Nutrient Requirements of Poultry, $9^{\text {th }}$ edn, Washington, DC, National Academy Press.

Ramasamy, T., Varshneya, C. and Katoch V. C., 2010. Immunoprotective effect of Seabuckthorn (Hippophae rhamnoides) and Glucomannan on T-2 toxin induced immunodepression in poultry. Veterinary Medicine International, 10:1-6.

Ramesh, B.K., Narayanaswamy, H.D., Satyanarayana, M. L., Suguna Rao and Srikrishna Isloor, 2014. Toxicological Evaluation of T-2 Toxin and Its Amelioration with Arginine and Vitamin E Supplementation in Broiler Chicken. International Journal of Livestock Research, 4(2):74-80
Snedecor, G.W. and Cochran, W.G., 1989. Statistical Methods. $8^{\text {th }} E d n$. Iowa State Univ. Press, Ames.

Tayade, C., Jaiswal, T. N., Mishra, S. C., and Koti, M., 2006. L-Arginine stimulates immune response in chickens immunized with intermediate plus strain of infectious bursal disease vaccine. Vaccine, 24:552-560.

Van Der Zijpp, A. J., 1983. Breeding for immune responsiveness and disease resistance. World's Poult. Sci. J., 39:118-131.

Watkins, B. A., 1991. Importance of essential fatty acids and their derivatives in poultry.J. Nutr., 121:1475-1485.

Wyatt, R.D., Hamilton, P.B. and Burmeister, H.R., 1973. The effects of T-2 toxin in broiler chicken. Poult. Sci., 52: 18531859.

Yohannes, T., Sharma, A.K., Singh, S.D. and Goswami, $\quad$ T.K., 2012. Immunopathological effects of experimental T-2 mycotoxocosis in broiler chicken co-infected with infectious bronchitis virus (IBV). Vet. Immunol. Immunopathol., 146: 245253.

Zhu, X.Y., Porter, R.E, Jr. and Hester, P.Y., 1999. Delayed type hypersensitivity reactions induced in broilers by killed Staphylococcus aureus. Poult. Sci., 78:1703-1710.

\section{How to cite this article:}

Ramesh, B.K., H.D. Narayanaswamy, M.L. Satyanarayana, Suguna Rao and Srikrishna Isloor. 2019. Effect of Arginine and Vitamin E Supplementation on Delayed Foot Web Reaction to Killed Staphylococcus aureus in Experimental T-2 Mycotoxicosis in Broiler Chicken. Int.J.Curr.Microbiol.App.Sci. 8(04): 1398-1405. doi: https://doi.org/10.20546/ijcmas.2019.804.162 